\title{
Twelve-Month Drug Cost Savings Related to Use of an Electronic Prescribing System With Integrated Decision Support in Primary Care
}

\author{
S. TROY MCMULLIN, PharmD; THOMAS P. LONERGAN, PharmD, MBA; and CHARLES S. RYNEARSON, RPh, MS
}

\begin{abstract}
OBJECTIVE: We reported previously the results of a 6-month controlled trial in which the use of a commercially available electronic prescribing system with integrated clinical decision support and evidence-based message capability was associated with significantly lower primary care drug costs. The original study focused on new prescriptions, defined as claims for a medication that the patient had not received in the previous 12 months. The main objectives of this follow-up report were to (a) determine if the 6-month savings on new prescriptions were sustained during 12 months of follow-up, (b) evaluate the impact of the computerized decision support system (CDSS) on all pharmacy claims and per-member-per-month (PMPM) expenditures, and (c) evaluate the prescribing behaviors within 8 high-cost therapeutic categories that were frequently targeted by the electronic messages to prescribers to help verify that the drug cost savings were due to the recommendations in the electronic prescribing system.
\end{abstract}

METHODS: Two database queries were performed to identify additional pharmacy claims data for all Network Health Plan patients who were cared for by the 38 primary care clinicians (32 physicians, 4 nurse practitioners, and 2 physician assistants) included in our original 6-month study. This follow-up analysis (a) identified all new prescription claims for the 2 groups of clinicians throughout the 12-month follow-up period (June 2002 through May 2003) and (b) assessed all pharmacy claims during the same 12-month period to provide more complete savings estimates and to examine between-group differences in PMPM expenditures.

RESULT S: During 12 months of follow-up, clinicians using the electronic prescribing system continued to have lower prescription costs than the controls. Clinicians using the electronic prescribing system had average costs for 26,674 new prescriptions that were $\$ 4.12$ lower (95\% confidence interval, $\$ 1.53-\$ 6.71$; $P=0.003$ ) and PMPM expenditures that were $\$ 0.57$ lower than expected based on the changes observed for 24,507 new prescriptions written by clinicians in the control group. The average drug cost savings on new prescriptions were \$482 per prescriber per month (PPPM), based upon prescription cost and \$465 PPPM based upon PMPM analysis. When all pharmacy claims $(156,429)$ were analyzed, the intervention group's average prescription cost was \$2.57 lower and their PMPM expenditures were \$1.07 lower than expected based on the changes observed in the control group. The average drug cost savings on all pharmacy claims were \$863 PPPM based on average prescription cost and $\$ 873$ PPPM based on PMPM analysis. The proportion of prescriptions for highcost drugs that were the target of the CDSS messages to prescribers was a relative $17.5 \%$ lower among the intervention group (35.8\%) compared with the control group (43.4\%; $P=0.03)$.

CONCLUSIONS: An electronic prescribing system with integrated decision support shifted prescribing behavior away from high-cost therapies and significantly lowered prescription drug costs. The savings associated with altered prescribing behavior offset the monthly subscription cost of the system.

KEYWORDS: Clinical decision support systems, Electronic prescribing, Ambulatory care information systems, Medical decision making, Computer-assisted, Medical informatics applications, Drug utilization

J Manag Care Pharm. 2005;11(4):322-32
S ome computerized decision support systems (CDSS) have been shown to influence prescribing decisions; however, most published studies have been conducted in hospital settings and examined internally developed CDSS that are not easily exported to other settings. ${ }^{1-5}$ Although a few trials have been performed in primary care, these have also typically used custom-built systems, and most have been performed in academically affiliated clinics, have limited their interventions to a single drug class or disease state, and provided relatively short follow-up. ${ }^{6-14}$ To our knowledge, there are no published studies that have adequately evaluated the long-term impact of commercially available CDSS or electronic prescribing products in a community-based primary care setting.

We reported previously the results of a 6-month controlled trial of a commercially available electronic prescribing system with integrated clinical decision support in which new primary care prescription costs were reduced by more than $10 \%$ per prescription. ${ }^{15}$ Because the original study focused only on new prescriptions (defined as a claim for a medication that the patient had not received in the previous 12 months), we were unable to fully assess the impact of the system on total pharmacy costs. The main objectives of this follow-up report were to determine if the 6-month savings on new prescriptions were sustained during a longer follow-up observation period (12 months) and to evaluate the impact of the CDSS on all phamacy claims (i.e., new prescriptions plus older prescriptions that were active prior to the intervention) and per-member-permonth (PMPM) expenditures.

To help verify that the system was effective at changing prescribing behavior, we also evaluated the utilization of drugs within 8 high-cost therapeutic categories that were targets of the CDSS messaging function. To our knowledge, this is the first controlled study that has formally investigated the impact

\section{Authors}

S. TROY MCMULLIN, Pha rmD, is a clinical researcher/writer and THOMAS P. LONERGAN, PharmD, MBA, is vice president, client services and clinical content, Department of Clinical Decision Support, Purkinje, St. Louis, Missouri; CHARLES S. RYNEARSON, RPh, MS, is director, pharmaceutical benefits, Network Health Plan and Affinity Health System, Menasha, Wisconsin.

AUTHOR CORRESPONDENCE: S. Troy McMullin, PharmD, Clinical Researcher, Department of Clinical Decision Support, Purkinje, 10426 Baur Blvd., St. Louis, MO 63132. Tel: (314) 993-4378; Fax: (314) 824-5082;

E-mail:tmcmullin@purkinje.com

Copyright $\odot$ 2005, Academy of Managed Care Pharmacy. All rights reserved. 
of a commercially available CDSS on a wide range of prescribing decisions in primary care for a period of at least 12 months.

\section{Methods}

\section{Description of the System}

The CDSS (Purkinje, St. Louis, MO) is an electronic prescribing system with integrated clinical decision support and messaging capabilities. The 2 key features of the messaging system are its ability to display diagnosis-specific recommendations throughout the electronic prescribing process and daily evidence-based messages. The brief "messages of the day" contain a concise summary of a recently published article or other important clinical information, with an emphasis on topics that support evidence-based, fiscally responsible prescribing (Figure 1). Most of these messages run within a few days or weeks of the original publication, depending on their importance. Summaries of landmark articles, new clinical guidelines, and other practice-changing studies are often repeated several times within the first few months of publication to increase awareness among clinicians. Payer-specific messages are also sent to the clinicians using the daily messaging function (e.g., payers may want to share information with clinicians regarding important formulary changes, specific prior authorization requirements, or selected mail-order programs). These messages automatically appear on the first screen that the clinicians see each day.

Electronic messages are also displayed during the prescribing process. The CDSS is connected to the medical practice management system so that the daily patient schedules for each clinician can be imported into the system. To enter a prescription in the CDSS, the clinician must first choose a patient and then select a diagnosis. Each clinician's most commonly used diagnoses are automatically displayed in the system. Less common diagnoses can be selected from categorized menus (e.g., gastrointestinal, cardiovascular) or by using a text-based search engine. After a diagnosis is selected, the CDSS displays a brief, diagnosisspecific message and a list of prewritten prescriptions (Figure 2). The diagnosis-specific messages automatically appear above the list of prewritten prescriptions, but they do not interfere with the prescribing process (i.e., they do not appear as pop-up messages or require physicians to take a specific action before they can prescribe a medication). Most diagnoses have 5 to 10 different messages that address various aspects of patient care. These messages are rotated every 3 to 6 weeks so that different messages appear on a regular basis.

All diagnosis-specific messages are hyperlinked to detailed therapeutic reviews that contain supporting evidence from the primary literature and comparative cost information. These reviews are updated every 3 to 6 months by the CDSSemployed clinical pharmacists and editorial staff. The daily messages and other evidence-based clinical content are also accredited for continuing medical education by the Washington University School of Medicine (St. Louis, MO).
The CDSS is sold by the vendor on a subscription basis for approximately $\$ 150$ per prescriber per month (PPPM). The CDSS operates on any Windows (95, 98, 2000, XP, or CE), Pocket PC, or Pocket IE-compatible device.

\section{Description of Study Sites and Baseline Matching Process}

The CDSS evaluation was conducted at Affinity Health System (Menasha, WI). Affinity Health System is an integrated delivery network that includes Network Health Plan. The Network Health Plan has 80,000 members in health maintenance organization and point-of-service products. Approximately $80 \%$ of the members were enrolled in a 3-tier pharmacy b e n e f it design during the study. Affinity Health System clinicians receive no financial incentives related to pharmacy costs for health plan members.

To assess the impact of the CDSS at Affinity Health System, we originally performed a 6-month nested cohort study. ${ }^{15}$ For that study, 19 primary care clinicians using the CDSS were matched with 19 control clinicians from the same medical group who were not yet using the system. The baseline process for matching clinicians was performed using pharmacy claims data for the 6-month period immediately preceding implementation of the CDSS (November 2001 through April 2002). The key prescribing statistics used in the matching process included the number of new medication claims, total drug ingredient cost for those claims, number of patients treated with a new medication, and use of specific high-cost therapeutic categories. The highcost therapeutic categories accounted for $77 \%$ of new drug expenditures at baseline and included medications used to treat common primary care conditions such as depression, gastroesophageal reflux disease, allergic rhinitis, upper respiratory infections, asthma, diabetes, hypertension, hyperlipidemia, arthritis, and headache disorders. Matching the 2 groups on their use of these therapeutic categories was intended to help ensure that clinicians treated similar types of conditions with similar types of medications.

The clinicians in each group were composed of 16 physicians and 3 allied health professionals (nurse practitioners and physician assistants have independent prescriptive authority in Wisconsin). The intervention group was composed of 13 physicians in family practice (68\%), 3 physicians in internal medicine (16\%), 2 nurse practitioners (11\%), and 1 physician assistant (5\%). The control group was composed of 9 physicians in family practice (47\%), 7 physicians in internal medicine (37\%), 2 nurse practitioners (11\%), and 1 physician assistant (5\%). The clinicians in the intervention and control groups were of similar age (average: 46 and 45 years, respectively) and had a similar number of years of clinical experience (average: 15 and 14 years, respectively). Intervention and control clinicians practiced in the same geographic regions. With the exception of a 9-physician practice location that included 2 physicians in the intervention group and 2 physicians in the control group, the 
Twelve-Month Drug Cost Savings Related to Use of an Electronic Prescribing System With Integrated Decision Support in Primary Care

\section{FIGURE 1 Examples of Messages Targeting High-Cost Therapeutic Categories}

DEPRESSION: Consider fluoxetine (\$16/month) for patients who need an SSRI. T he re is no convincing evidence that any particular SSRI is consistently more effective or better tolerated than another. For example, 2 large randomized trials (857 participants) found no diffe rence in efficacy or tolerability when fluoxetine, paroxetine, and sertraline were compared. Response rates, treatment-emergent side effects, and discontinuation rates were almost identical with all 3 SSRIs (Maurizio F. J Clin Psychopharmacol. 2002;22:137-47; Kroenke K. JAMA. 2001;286:2947-55). Generic fluoxetine is significantly less expensive than escitalopram (Lexapro: \$67/month), citalopram (Celexa: $\$ 69 /$ month), paroxetine (Paxil: $\$ 71 /$ month), sertraline (Zoloft: $\$ 73 /$ month), or extended release fluoxetine (Prozac Weekly: \$82/month)

GERD: Most patients with persistent heartburn do not need a PPI Endoscopic studies suggest that at least $65 \%$ to $75 \%$ of patients with chronic heartburn will have nonerosive disease. This is an important consideration because almost all studies showing superiority of PPIs over H2 blockers were performed in the small subset of patients with documented erosive esophagitis. All 4 comparative trials $(2,154$ participants) that were performed exclusively in patients with uninvestigated GERD or nonerosive GERD have found that $\mathrm{H} 2$ blockers and PPIs provide comparable improvements in symptoms and quality of life. In addition, most patients reported being completely free of symptoms for 5 to 6 days/week, whether they received an H2 blocker or PPI. For patients with persistent heartburn, ranitidine ( $\$ 11 /$ month) is one of the least expensive treatment options.

RHINITIS: Nasal steroids are more effective than nonsedating antihistamines in allergic rhinitis. In a long-term trial of 143 patients with perennial rhinitis, intranasal budesonide (Rhinocort) resulted in a significantly greater reduction in allergy symptom scores than cetirizine (Zyrtec). At the 6- and 12-month follow-up, nasal symptoms were decreased by $45 \%$ to $46 \%$ with budesonide versus $26 \%$ to $29 \%$ with cetirizine. Patients treated with budesonide also experienced a higher percentage of rhinitis-free days ( $45 \%$ versus $26 \%$ ) and were more likely to report satisfactory control of symptoms ( $74 \%$ versus $50 \%$ ). E y e symptoms were decreased slightly more with budesonide (36\% to $43 \%$ versus $18 \%$ to $28 \%$ ); however, this diffe rence did not reach statistical significance (Rinne J. J Allergy Clin Immunol. 2002;109:426-32). Similar results have been observed in at least 10 short-term seasonal rhinitis trials. In these trials, allergy symptoms were typically decreased by $30 \%$ to $50 \%$ with nasal steroids and $20 \%$ to $30 \%$ with nonsedating antihistamines

INFECTIONS: Consider doxycycline (\$6) instead of azithromycin (Zithromax: \$48) for adults with acute bronchitis. According to guidelines from the American College of Physicians and American Society of Internal Medicine, bacteria cause fewer than $5 \%$ to $10 \%$ of uncomplicated acute bronchitis cases and, therefore, routine antibiotic therapy is not recommended. In cases where bacteria are suspected, therapy should be directed against atypical organisms such as mycoplasma and chlamydia because these are among the most common nonviral pathogens isolated from patients with acute bronchitis. The re is no evidence that streptococcus, haemophilus, or moraxella cause acute bronchitis in patients without underlying lung disease. Doxycycline provides excellent coverage against atypical organisms at a fraction of what azithromycin (Zithromax) costs (Gonzales R. Ann Intern Med. 2001;134:521-29).

PAIN/MIGRAINE: Celecoxib (Celebrex: $\$ 80$ to $\$ 160 /$ month) does not appear to be safer than nonselective NSAIDS. Although it was hoped that COX-2 inhibitors would cause fewer serious side effects than nonselective NSAIDS, data $f$ rom clinical trials suggest that these agents are not associated with dramatically improved safety or tolerability. In the CLASS studies $(n=8,059)$, celecoxib $400 \mathrm{mg}$ BID was compared with ibuprofen $800 \mathrm{mg}$ TID and diclofenac $75 \mathrm{mg}$ BID. During 12 months of follow-up, there was no statistically significant difference in the incidence of serious GI complications $(0.4 \%$ versus $0.5 \%$ versus $0.6 \%$ ), GI side effects (dyspepsia: $17 \%$ versus $17 \%$ versus $20 \%$, abdominal pain: $12 \%$ versus $11 \%$ versus $17 \%$ ), or overall tolerability (withdrawals due to adverse effects: $23 \%$ versus $23 \%$ versus $27 \%$ ). The incidence of serious cardiovascular events was also similar with all 3 agents (Lu HL. Statistical Reviewer Briefing Document for the FDA Advisory Committee)

Primary care guidelines recommend NSAIDs as first-line migraine therapy. According to guidelines from the American Academy of Family Physicians and American College of Physicians, triptans and other migraine-specific therapies should be reserved for patients whose migraines do not respond to NSAIDs. These guidelines are fairly consistent with older guidelines from the American Academy of Neurology and the U.S. Headache Consortium, but they place more emphasis on the use of NSAIDs for severe migraines. Of note, nearly all doubleblind trials that have compared NSAIDS and triptans in patients with moderate or severe migraines have found that NSAIDs provide comparable efficacy and fewer side effects. NSAIDS are significantly less expensive than triptans (Snow V. Ann Intern Med. 2002;137:840-49).

HYPERTENSION: Hypertension guidelines recommend a thiazide-type diuretic as initial therapy for most patients. Despite data supporting the efficacy of newer more expensive drug classes, treatment guidelines still recommend thiazide-type diuretics for first-line therapy of hypertension, unless there are compelling indications to use a different drug class. Other inexpensive drug classes proven to decrease the risk of serious cardiovascular outcomes include ACE inhibitors and beta-blockers. Compelling indications for the use of these drug classes include heart failure, history of myocardial infarction or stroke, diabetes, and renal disease (JNC 7 Report: Chobanian A. JAMA. 2003;289:2560-72).

ASTHMA: New data confirm that montelukast (Singulair: \$90/mo) should not be used first-line for asthma. The National Asthma Education and Prevention Program Expert Panel Report recommends inhaled steroids as preferred first-line therapy for most adults and children with persistent asthma. Two systematic reviews recently reported that asthmatics treated with leukotriene modifiers (e.g., montelukast) were 60\% more likely to suffer an exacerbation and twice as likely to require hospitalization as patients treated with inhaled steroids. Inhaled steroids also resulted in fewer emergency room visits, lower asthma-related medical costs, larger improvements in lung function and symptom scores, and greater reductions in nighttime awakenings and need for rescue albuterol than leukotriene modifiers (Ducharme FM. BMJ. 2003;326:621-25, Halpern MT. J Fam Pract. 2003;52:382-89).

Salmeterol (Serevent) may be superior to montelukast (Singulair) as add-on therapy in asthma. The National Asthma Education and Prevention Program Expert Panel Report recommends a long-acting beta agonist as preferred add-on therapy in patients with moderate persistent asthma. A recent long-term noninferiority study randomized 1,473 asthmatics with symptoms not adequately controlled by an inhaled steroid to 48 weeks of add-on therapy with either salmeterol $42 \mathrm{mcg}$ BID or montelukast $10 \mathrm{mg} /$ day. During the trial, salmeterol resulted in statistically greater improvements in lung function, symptom scores, rescue albuterol use, nighttime awakenings, symptom-free days, and quality-of-life scores than montelukast. The difference in rate of exacerbations ( $17 \%$ versus $20 \%$ ) also favored salmeterol and failed to meet the preplanned criteria for claiming that montelukast was not inferior to salmeterol (Ilowite J. Ann Allergy Asthma Immunol. 2004;92:641-48).

DIABETES: New data confirm that pioglitazone (Actos) and rosiglitazone (Avandia) increase the risk of heart failure. A retrospective cohort study of 33,544 diabetics reported that patients who were treated with glitazones had a significantly higher incidence of new-onset heart failure than those treated with other oral antidiabetic agents (8.8\% versus 5.5\%). During 40 months of followup, patients treated with glitazones also were more likely to be hospitalized for heart failure (2.5\% versus $1.0 \%$ ) (Delea TE. Diabetes Care 2003;26:2983-89). Unlike sulfonylureas and metformin, glitazones have not been shown to prevent diabetic complications. Given the lack of outcomes data with glitazones and the increased risk of cardiovascular complications, these agents should be reserved for add-on therapy in patients who have not met their HbAlc goal with other agents.

ACE = angiotensin-converting enzyme; BID = twice daily; CLASS = Celecoxib Long-Term Arthritis Safety Study; COX-2=cyclooxygenase-2; FDA=U.S. Food and Drug Administration; GERD= gastroesophageal reflux disease; GI=gastrointestinal; HbAlc=glycated hemoglobin; $H 2=$ histamine-2; JNC $7=$ Seventh Report of the Joint National Committee on Prevention, Detection, Evaluation, and Treatment of High Blood Pressure; NSAID=nonsteroidal anti-inflammatory drug; PPI= proton pump inhibitor; SSRI=selective serotonin reuptake inhibitor; $T I D=$ thrice daily. 


\section{FIGURE 2 Examples of Electronic Messages and Prewritten Prescriptions for Prescribers}

After a diagnosis is selected, the physician is presented with a screen that contains a brief clinical message (highlighted sentence in top third of screen), diagnosisspecific prewritten prescriptions, formulary information (Form), and drug monographs (Drug Info). When users click on the hyperlinked message, they are taken to an evidence-based review that explains the rationale for the message. Links to detailed therapeutic reviews, patient counseling tips, and printable patient education materials for the current diagnosis are also available by selecting the Info button in the top right corner.

\begin{tabular}{|c|c|c|c|c|c|c|c|c|c|c|}
\hline Home & \multicolumn{2}{|c|}{ Find Patient } & Diagnoses & Prescriptions & Allergies/Alerts & \multicolumn{2}{|c|}{ Patient Details } & Reports & Info & Help \\
\hline \multicolumn{11}{|c|}{ Name: Wellinx Patient DOB: 10/18/1952 Formulary: Network Health Plan of Wisconsin } \\
\hline \multicolumn{6}{|c|}{ Top Rx for 250.02: DIABETES MELLITUS TYPE II } & \multicolumn{2}{|c|}{ Search by Keyword } & $\underline{\text { Back }}$ & \multicolumn{2}{|l|}{ Cancel } \\
\hline & & Form & \multicolumn{2}{|c|}{ Drug/Dosage } & Sig & Qty & Refill & PRN & Fill & Info \\
\hline \multicolumn{11}{|c|}{ Sulfonylureas and metformin proven to decrease diabetic complications; glitazone outcomes unknown } \\
\hline More & $\underline{\text { Edit }}$ & Pref & \multicolumn{2}{|c|}{$\underline{\text { GLYBURIDE } 5 \text { MG TABLET }}$} & $1 \mathrm{QD}$ & 30 & 6 & N & Fax & Drug Info \\
\hline More & $\underline{E d i t}$ & Pref & \multicolumn{2}{|c|}{$\underline{\text { GLIPIZIDE } 5 \text { MG TABLET }}$} & $1 \mathrm{QD}$ & 30 & 6 & N & Fax & Drug Info \\
\hline More & $\underline{\text { Edit }}$ & Pref & \multicolumn{2}{|c|}{ METFORMIN 500 MG TABLET } & $1 \mathrm{BID}$ & 60 & 6 & $\mathrm{~N}$ & Fax & Drug Info \\
\hline More & Edit & Cov & \multicolumn{2}{|c|}{ GLUCOVANCE 2.5/500 MG TABLET } & $1 \mathrm{BID}$ & 60 & 6 & N & Fax & Drug Info \\
\hline More & $\underline{\text { Edit }}$ & $\underline{\text { Cov }}$ & \multicolumn{2}{|c|}{$\underline{\text { HUMULIN N } 100 \text { UNITS/ML }}$} & UT DICT & 10 & 6 & N & Fax & Drug Info \\
\hline More & Edit & $\underline{\text { Cov }}$ & \multicolumn{2}{|c|}{ HUMULIN R 100 UNITS/ML } & UT DICT & 10 & 6 & N & Fax & Drug Info \\
\hline More & $\underline{\text { Edit }}$ & $\underline{\text { Cov }}$ & \multicolumn{2}{|c|}{ HUMULIN 70/30 100 UNITS/ML } & UT DICT & 10 & 6 & $\mathrm{~N}$ & Fax & Drug Info \\
\hline$\underline{\text { More }}$ & $\underline{\text { Edit }}$ & $\underline{\mathrm{H} / \mathrm{C}}$ & \multicolumn{2}{|c|}{$\underline{\text { ACTOS } 15 \text { MG TABLET }}$} & $1 \mathrm{QD}$ & 30 & 6 & $\mathrm{~N}$ & Fax & Drug Info \\
\hline \multicolumn{2}{|c|}{\begin{tabular}{l|l} 
Home & I \\
\end{tabular}} & Find Patient & Diagnoses & Prescriptions & Allergies/Alerts & \multicolumn{2}{|c|}{ Patient Details } & Reports & Info & Help \\
\hline \multicolumn{11}{|c|}{ Name: Wellinx Patient DOB: 05/27/1974 Formulary: Network Health Plan of Wisconsin } \\
\hline \multicolumn{6}{|c|}{ Top Rx for 311: DEPRESSION, NOS } & \multicolumn{2}{|c|}{ Search by Keyword } & $\underline{\text { Back }}$ & \multicolumn{2}{|l|}{ Cancel } \\
\hline & & Form & Drug/Dosage & & Sig & Qty & Refill & PRN & Fill & Info \\
\hline \multicolumn{11}{|c|}{ Studies suggest all SSRIs have similar efficacy and tolerability; generic fluoxetine is least expensive } \\
\hline More & $\underline{\text { Edit }}$ & Pref & \multicolumn{2}{|c|}{ FLUOXETINE 20 MG CAPSULE } & $1 \mathrm{QD}$ & 30 & 6 & N & Fax & Drug Info \\
\hline More & $\underline{\text { Edit }}$ & Pref & \multicolumn{2}{|c|}{ DESIPRAMINE 50 MG TABLET } & $1 \mathrm{QHS}$ & 30 & 6 & N & Fax & Drug Info \\
\hline More & Edit & Pref & \multicolumn{2}{|c|}{ NORTRIPTYLINE 50 MG CAPSULE } & 1 QHS & 30 & 6 & $\mathrm{~N}$ & Fax & Drug Info \\
\hline More & Edit & $\underline{\text { Cov }}$ & \multicolumn{2}{|c|}{ CELEXA 20 MG TABLET } & $1 \mathrm{QD}$ & 30 & 6 & $\mathrm{~N}$ & Fax & Drug Info \\
\hline More & $\underline{\text { Edit }}$ & $\underline{\text { Cov }}$ & \multicolumn{2}{|c|}{$\underline{P A X I L} 20$ MG TABLET } & $1 \mathrm{QD}$ & 30 & 6 & N & Fax & Drug Info \\
\hline More & $\underline{\text { Edit }}$ & $\underline{\text { Cov }}$ & \multicolumn{2}{|c|}{ ZOLOFT 100 MG TABLET } & $1 \mathrm{QD}$ & 30 & 6 & N & Fax & Drug Info \\
\hline More & $\underline{\text { Edit }}$ & $\underline{\text { Cov }}$ & \multicolumn{2}{|c|}{ BUPROPION 100 MG TABLET } & $1 \mathrm{BID}$ & 60 & 6 & N & Fax & Drug Info \\
\hline$\underline{\text { More }}$ & $\underline{\text { Edit }}$ & $\underline{\mathrm{H} / \mathrm{C}}$ & EFFEXOR XR 75 & CAPSULE & $1 \mathrm{QHS}$ & 30 & 6 & $\mathrm{~N}$ & Fax & Drug Info \\
\hline
\end{tabular}

BID = twice daily; $C o v=$ covered; $H / C=$ higher copay; $N=n o ; N O S=$ not otherwise specified; Pref = preferred; $P R N=$ as needed; $Q D=$ once daily; QHS =at bedtime; UT DICT $=$ as directed.

clinicians practiced in separate office sites. During the study, both groups were managed under the same health plan restrictions, including periodic meetings with health plan pharmacists. The prescribing clinicians and pharmacists were not aware of study objectives during the baseline or follow-up periods.

In our original report, we found that the electronic prescribing system was associated with combined mean savings of $\$ 4.16$ per new prescription, derived from a decrease of $\$ 1.25$ per prescription $(-3.2 \%)$ for the intervention group and an average increase of $\$ 2.91$ per prescription $(+7.6 \%)$ for the control group, $P=0.02 .{ }^{15} \mathrm{~A}$ new prescription was defined as a claim for a medication that the patient had not been treated with in the previous 12 months. The new prescription costs included the cost for the original prescription (i.e., first fill) plus all refills that were obtained for that medication during the follow-up period. We limited the analysis to new prescriptions and their refills because we were most interested in assessing the impact of the CDSS on new therapeutic decisions and because we were concerned that including refills of chronic medications that were started prior to implementation of the CDSS (i.e., "old" 


\section{TABLE 1 High-Cost Drugs and Preferred-Drug Alternatives}

\begin{tabular}{|c|c|c|}
\hline Therapeutic Categories & High-Cost Drugs & Preferred Drugs \\
\hline Depression & $\begin{array}{l}\text { Citalopram, escitalopram, fluoxetine-weekly, sertraline, } \\
\text { paroxetine }\end{array}$ & Generic fluoxetine \\
\hline GERD & $\begin{array}{l}\text { Proton pump inhibitors (esomeprazole, lansoprazole, } \\
\text { omeprazole, pantoprazole, rabeprazole) }\end{array}$ & $\begin{array}{l}\mathrm{H} 2 \text { receptor antagonists (generic cimetidine, generic } \\
\text { famotidine, generic nizatidine, generic ranitidine) }\end{array}$ \\
\hline Rhinitis & $\begin{array}{l}\text { Low-sedating antihistamines (cetirizine, fexofenadine, } \\
\text { loratadine, desloratadine) }\end{array}$ & $\begin{array}{l}\text { Intranasal corticosteroids (beclomethasone, budesonide, } \\
\text { flunisolide, fluticasone, mometasone, triamcinolone) }\end{array}$ \\
\hline Infections & $\begin{array}{l}\text { Broad-spectrum antibiotics (amoxicillin/clavulanate, } \\
\text { azithromycin, cefaclor, cefadroxil, cefdinivir, cefpodoxime, } \\
\text { cefprozil, cefuroxime, ciprofloxacin, clarithromycin, } \\
\text { gatifloxacin, levofloxacin, loracarbef, moxifloxacin, ofloxacin) }\end{array}$ & $\begin{array}{l}\text { Narrow-spectrum antibiotics (generic amoxicillin, generic } \\
\text { cephalexin, generic clindamycin, generic dicloxacillin, } \\
\text { generic doxycycline, generic erythromycin, generic } \\
\text { nitrofurantoin, generic minocycline, generic penicillin, } \\
\text { generic trimethoprim-sulfamethoxazole, generic tetracycline) }\end{array}$ \\
\hline Pain/migraine & $\begin{array}{l}\text { COX-2 inhibitors and 5-HTl agonists (triptans) } \\
\text { (almotriptan, celecoxib, frovatriptan, naratriptan, rizatriptan, } \\
\text { rofecoxib, sumatriptan, valdecoxib zolmitriptan) }\end{array}$ & $\begin{array}{l}\text { NSAIDs (generic diclofenac, generic etodolac, generic fenoprofen, } \\
\text { generic flurbiprofen, generic ibuprofen, generic indomethacin, } \\
\text { generic ketoprofen, generic ketorolac, generic meloxicam, generic } \\
\text { nabumetone, generic naproxen, generic oxaprozin, generic piroxicam, } \\
\text { generic sulindac) }\end{array}$ \\
\hline Hypertension & $\begin{array}{l}\text { Angiotensin receptor blockers and calcium channel blockers } \\
\text { (amlodipine, candesartan, diltiazem, felodipine, irbesartan, } \\
\text { isradipine, losartan, olmesartan, telmisartan, nifedipine, } \\
\text { valsartan, verapamil) }\end{array}$ & $\begin{array}{l}\text { Thiazide diuretics, beta-blockers or ACE inhibitors (generic } \\
\text { atenolol, benazapril, bisoprolol, generic captopril, carvedilol, } \\
\text { generic chlorthalidone, enalapril, fosinopril, generic } \\
\text { hydrochlorothiazide, labetalol, lisinopril, metoprolol, generic } \\
\text { p ropranolol, quinapril, ramipril, metoprolol, nadolol, trandolapril) }\end{array}$ \\
\hline Asthma & $\begin{array}{l}\text { Leukotriene receptor antagonists (montelukast, zafirlukast, } \\
\text { zileuton) }\end{array}$ & $\begin{array}{l}\text { Inhaled corticosteroids or long-acting beta agonists } \\
\text { (beclomethasone, budesonide, flunisolide, fluticasone, formoterol, } \\
\text { salmeterol, triamcinolone) }\end{array}$ \\
\hline Diabetes & Thiazolidinediones (glitazones) (pioglitazone, rosiglitazone) & Glyburide, glipizide, metformin \\
\hline
\end{tabular}

ACE = angiotensin-converting enzyme; COX-2 = cyclooxygenase $-2 ;$ GERD = gastroesophageal reflux disease $;$ H2= histamine-2; 5-HT1 = 5-hydroxytryptamine 1;

NSAID = nonsteroidal anti-inflammatory drug.

prescriptions) might mask the overall impact in a short-term trial. The decision to analyze new prescription claims was made a priori, before the matching process or original study period began.

During the original study, we discovered that new prescriptions accounted for a relatively small proportion of all pharmacy claims $(<30 \%$ during the original 6-month study period). In October 2003, 2 subsequent database queries were performed to identify additional Network Health Plan pharmacy claims for the 2 groups of physicians included in our original study. We first identified new prescription claims and their refills for the 2 groups of clinicians throughout the 12-month follow-up period (June 2002 through May 2003). Second, data were summarized for all pharmacy claims and other key utilization statistics for the 2 groups over the same 12-month period. As in the original report, all queries were limited to prescriptions that were written by the patient's primary care provider (i.e., we excluded prescriptions written for these health plan members by specialists or other prescribers who were not the assigned primary care provider for the patient).

\section{Outcome Measures}

The follow-up database queries were used to determine if the savings on new prescriptions were sustained during 12 months of follow-up and to assess the impact of the CDSS on the cost of all pharmacy claims (i.e., including chronic medications that were active prior to CDSS implementation). It is necessary to consider all pharmacy claims for several reasons, including the fact that a preexisting prescription may be replaced by a new prescription for an alternate drug for the same indication. In other words, cost savings can accrue from new prescriptions written for drugs new to a given patient as well as the discontinuation of drugs (e.g., nonpreferred or target drugs) that are replaced by alternate (e.g., preferred) drugs for the same indication. PMPM drug expenditure was an important secondary measure.

To help verify that the savings were because of the electronic prescribing system's recommendations, we also evaluated the prescribing patterns for the intervention and control groups during the 12-month follow-up period by comparing new prescriptions (and their refills) for specific high-cost drug classes and preferred-drug classes within 8 therapeutic categories (Table 1). Each of the 8 therapeutic categories contains medications that are frequent targets of the CDSS messages to prescribers. Each of these therapeutic categories has an equally appropriate, low-cost alternative that is frequently recommended by the system. 
TABLE 2 Summary of Pharmacy Claims and Prescription Costs*

\begin{tabular}{|c|c|c|c|c|c|c|}
\hline & \multicolumn{2}{|c|}{$\begin{array}{c}\text { Baseline (6 Months: } \\
\text { November 2001-April 2002) }\end{array}$} & \multicolumn{2}{|c|}{$\begin{array}{l}\text { Follow-up (12 Months: } \\
\text { June 2002-May 2003) }\end{array}$} & \multicolumn{2}{|c|}{$\begin{array}{l}\text { Difference From Baseline } \\
\text { to Follow-up (\%) }\end{array}$} \\
\hline & $\begin{array}{l}\text { Intervention Group } \\
\qquad(\mathrm{n}=19)\end{array}$ & $\begin{array}{l}\text { Control Group } \\
\quad(n=19)\end{array}$ & $\begin{array}{l}\text { Intervention Group } \\
\qquad(\mathrm{n}=19)\end{array}$ & $\begin{array}{l}\text { Control Group } \\
\quad(n=19)\end{array}$ & $\begin{array}{c}\text { Intervention Group } \\
(\mathrm{n}=19)\end{array}$ & $\begin{array}{l}\text { Control Group } \\
\quad(\mathrm{n}=19)\end{array}$ \\
\hline $\begin{array}{l}\text { Average number of members } \\
\text { per month }\end{array}$ & 15,257 & 15,349 & 15,497 & 14,488 & $240(1.6 \%)$ & $-861(-5.6 \%)$ \\
\hline Total member-months & 91,542 & 92,094 & 185,959 & 173,852 & 94,417 & 81,758 \\
\hline $\begin{array}{l}\text { Average number of members } \\
\text { per physician-month }\end{array}$ & 803 & 808 & 816 & 763 & $13(1.6 \%)$ & $-45(-5.6 \%)$ \\
\hline $\begin{array}{l}\text { Number of pharmacy claims } \ddagger \\
\text { New prescriptions and their refills } \\
\text { New prescriptions PMPM }\end{array}$ & $\begin{array}{l}9,571 \\
0.105\end{array}$ & $\begin{array}{l}9,627 \\
0.105\end{array}$ & $\begin{array}{r}26,674 \\
0.143\end{array}$ & $\begin{array}{r}24,507 \dagger \\
0.141\end{array}$ & $\begin{array}{c}17,103 \\
0.038(36.2 \%)\end{array}$ & $\begin{array}{c}14,880 \\
0.036(34.3 \%)\end{array}$ \\
\hline $\begin{array}{l}\text { Other (refilled) prescriptions } \\
\text { Other prescriptions PMPM }\end{array}$ & $\begin{array}{r}25,387 \\
0.277\end{array}$ & $\begin{array}{r}29,615 \\
0.322\end{array}$ & $\begin{array}{r}49,867 \\
0.268\end{array}$ & $\begin{array}{r}55,381 \\
0.319\end{array}$ & $\begin{array}{c}24,480 \\
-0.009(-3.3 \%)\end{array}$ & $\begin{array}{c}25,766 \\
-0.003(-0.9 \%)\end{array}$ \\
\hline $\begin{array}{l}\text { Total for all pharmacy claims } \\
\text { Total prescriptions PMPM }\end{array}$ & $\begin{array}{r}34,958 \\
0.382\end{array}$ & $\begin{array}{r}39,242 \\
0.426\end{array}$ & $\begin{array}{r}76,541 \\
0.412\end{array}$ & $\begin{array}{r}79,888 \\
0.460\end{array}$ & $\begin{array}{r}41,583 \\
0.030(7.9 \%)\end{array}$ & $\begin{array}{r}40,646 \\
0.034(8.0 \%)\end{array}$ \\
\hline $\begin{array}{l}\text { Average cost per prescription } \\
\text { New prescriptions and their refills } \\
\text { Other (refilled) prescriptions } \\
\text { Total for all pharmacy claims }\end{array}$ & $\begin{array}{l}\$ 41.96 \\
\$ 47.92 \\
\$ 46.29\end{array}$ & $\begin{array}{l}\$ 41.79 \\
\$ 47.68 \\
\$ 46.24\end{array}$ & $\begin{array}{l}\$ 40.96 \\
\$ 48.55 \\
\$ 45.91\end{array}$ & $\begin{array}{l}\$ 45.54 \\
\$ 49.71 \\
\$ 48.43\end{array}$ & $\begin{array}{l}-\$ 1.00(-2.4 \%) \\
\$ 0.63(1.3 \%) \\
-\$ 0.38(-0.8 \%)\end{array}$ & $\begin{array}{l}\$ 3.75(9.0 \%) \\
\$ 2.03(4.3 \%) \\
\$ 2.19(4.7 \%)\end{array}$ \\
\hline $\begin{array}{l}\text { PMPM expenditures } \\
\text { New prescriptions and their refills } \\
\text { Other (refilled) prescriptions } \\
\text { Total for all pharmacy claims }\end{array}$ & $\begin{array}{r}\$ 4.39 \\
\$ 13.29 \\
\$ 17.68\end{array}$ & $\begin{array}{r}\$ 4.37 \\
\$ 15.33 \\
\$ 19.70\end{array}$ & $\begin{array}{r}\$ 5.88 \\
\$ 13.02 \\
\$ 18.90\end{array}$ & $\begin{array}{r}\$ 6.42 \\
\$ 15.83 \\
\$ 22.25\end{array}$ & $\begin{array}{c}\$ 1.49(33.9 \%) \\
-\$ 0.27(-2.0 \%) \\
\$ 1.22(6.9 \%)\end{array}$ & $\begin{array}{l}\$ 2.05(46.9 \%) \\
\$ 0.50(3.3 \%) \\
\$ 2.55(12.9 \%)\end{array}$ \\
\hline
\end{tabular}

* The data are presented as simple averages and represent all pharmacy claims and prescription costs prior to being adjusted for the impact of patient clustering. Prescription costs are the drug ingredient cost recorded in pharmacy claims.

$\dagger$ Fifteen control clinicians were using the computerized decision support system by the end of the 12-month observation period. The pharmacy claims data include 4,800 new prescriptions that were filled after the date that these clinicians started using the system.

\# "New prescription" was defined as a claim for a medication that the patient had not had a claim for within the previous 12 months.

PMPM = per member per month.

\section{Statistical Analysis}

All claims data were supplied by the health plan. The betweengroup differences in average cost for new prescriptions and the prescription ratios within the targeted high-cost categories were independently analyzed by an outside statistical consultant (Waterman Research Solutions, St. Louis, MO). The datasets containing all pharmacy claims and PMPM expenditures did not undergo statistical analysis because these data were not provided in sufficient detail to allow correction for the impact of patient clustering. In this study, patient clustering is an important consideration since the intervention occurred at the clinician level but data were analyzed at the patient level (i.e., the pharmacy claims for the patients assigned to each primary care practitioner). Unit of analysis errors, which occur when differences between the unit of allocation (e.g., physician) and unit of analysis (e.g., each patient's pharmacy claims data) are not accounted for, have been a problem with many prior CDSS and quality improvement studies. In one review, for example, $10(42 \%)$ of 24 studies assessing the impact of a CDSS failed to account for patient clustering in their analyses. ${ }^{16}$ In a review of studies assessing physicians' patient care behaviors, unit of analysis errors were noted in 38 (70\%) of 54 studies. $^{17}$

Study designs that allocate all patients treated by an individual clinician to the same group need to be analyzed differently from those in which patients are randomly assigned to groups. Allocating group assignment by clinician (i.e., cluster allocation) violates the assumption of independence, which is a requirement of most standard statistical tests. In this case, the assumption of independence is violated because 2 patients who receive care from the same clinician may be more likely to receive similar treatments than if each patient was treated by a different clinician. If standard statistical tests were used, each patient in a clinician's practice would be treated as an independent observation despite the fact that the clinician may have a certain practice style that results in all patients with a specific condition being treated essentially the same. Failure to account for the correlation among patients treated by the same clinician results in confidence intervals that are artificially narrow and $P$ values 


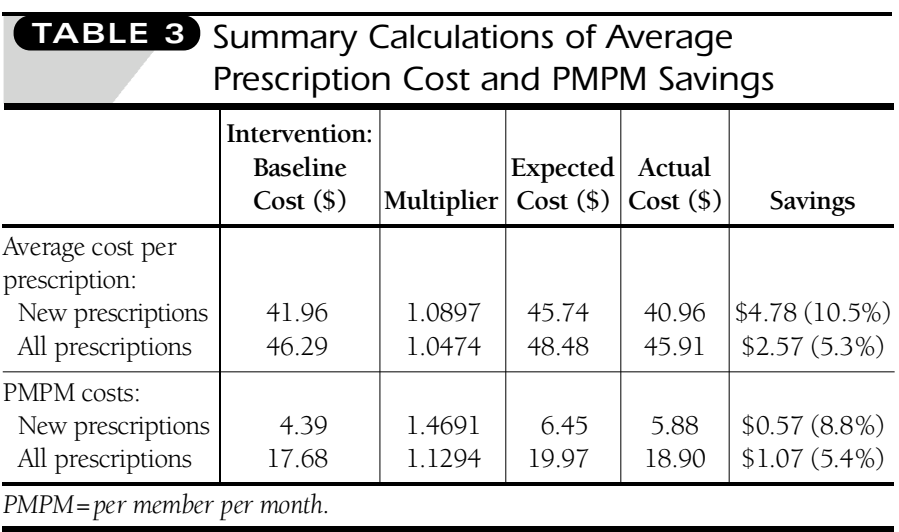

that are artificially low. For example, the new prescription savings in our original study would have been reported as $\$ 4.65$ (95\% confidence interval $[\mathrm{CI}], \$ 2.95-\$ 6.37 ; \mathrm{P}<0.001$ ) per prescription if the data were analyzed using standard statistical tests. In the cluster-adjusted analyses, the intervention effect was smaller ( $\$ 4.16$ per prescription), the confidence intervals were wider (95\% CI, $\$ 0.84-\$ 7.49$ ), and the $P$ value was 0.02 . These data demonstrate how studies that do not account for patient clustering could mistakenly report a statistically significant difference when no true difference exists.

To adjust for patient clustering by prescriber, we used a mixed model analysis of variance for continuous variables and generalized mixed linear model (using a logit link function and a binomially distributed error term) for dichotomous variables. Outcomes were analyzed by categorical study group (Intervention versus Control), time period (Baseline versus Study Period), and their interaction (Group-Time interaction). Marginal means and inferential tests of baseline differences and intervention effects were calculated in a manner that corrects standard errors and $P$ values for patient clustering. ${ }^{18}$ Two-tailed tests of significance were used and $P<0.05$ was selected for the level of statistical significance. All of the follow-up analyses on new prescriptions were performed using SAS/STAT Software Changes and Enhancements, Release 8.2 (Cary, NC: SAS Institute, Inc; 2001).

Although we were able to perform statistical analyses on the new prescriptions, the level of claim detail necessary to correct for patient clustering was not available from the queries on all pharmacy claims or for calculating PMPM expenditures. For the PMPM and all prescription claim outcome measures, the health plan only provided a high-level summary of key statistics, such as total drug ingredient cost, total number of pharmacy claims, and total member months for each group. Pharmacy claim detail for each prescription that was filled was not available to the investigators. Savings were therefore estimated by comparing growth rates in the average drug cost per prescription and PMPM expenditures throughout the 12-month follow-up period. Growth rates were normalized using the methodology proposed by the Centers for Medicare and Medicaid Services physician group demonstration project. ${ }^{19}$ This method corrects for baseline differences between groups by using the observed change in the control group to calculate the expected values in the intervention group. The difference between the intervention group's expected values and their actual values is used to estimate health plan savings.

Because it was not possible to perform statistical analyses on the datasets containing all pharmacy claims or PMPM expenditures, these results should be interpreted with caution. It is also important to note that we did not correct any of our analyses for the impact of cross-contamination. After the original 6-month study period ended, the CDSS was implemented in the offices of approximately 2 to 4 control clinicians per month during the second 6 months of the follow-up period. Overall, the 15 control clinicians who were converted to the CDSS at some time during the second-half of the 365-day follow-up period used the system for an average of 115 days (median 88 days). Therefore, the prescription data shown in Table 2 for 24,507 new and refill prescriptions written by the original 19 control primary care physicians include 4,800 new prescriptions (19.6\%) that were filled after control clinicians started using the CDSS. This intent-to-treat method of analysis is conservative and most likely understates the actual savings associated with prescribers using the CDSS.

\section{Results}

\section{Twelve-Month Analyses of New Prescription Claims}

Use of the CDSS was associated with a sustained reduction in prescription costs. Over the 12-month follow-up period, the average cost per new prescription decreased by $\$ 1.00(-2.4 \%)$ in the intervention group while it increased by $\$ 3.75$ (9.0\%) in the control group (Table 2). This $9.0 \%$ increase observed in the control group translates into an average $\$ 45.74$ expected cost per new prescription in the intervention group (109\% of the baseline average cost of \$41.96). During the study period, patients treated by physicians in the intervention group filled 26,674 new prescriptions at an average cost of $\$ 40.96$. The difference between the expected cost $(\$ 45.74)$ and the actual cost (\$40.96) represents savings of $\$ 4.78$ (10.5\%) per new prescription (Table 3). After correcting for the impact of patient clustering, the savings were calculated to be $\$ 4.12$ (95\% CI, $\$ 1.53-\$ 6.71 ; P=0.003)$ or $9.0 \%$ per new prescription. Based on this difference, the total 12-month savings on new prescriptions were $\$ 109,897$ or an average of $\$ 482$ PPPM.

Since there was little difference between the 2 groups in the absolute change in prescription utilization (an increase of 0.038 prescriptions PMPM [36.2\%] in the intervention group versus 0.036 prescriptions PMPM [34.3\%] in the control group) (Table 2), similar results were observed when the new prescription savings were calculated on a PMPM basis. During the 12-month follow-up period, PMPM expenditures for new prescriptions 
increased by $\$ 1.49$ (33.9\%) and $\$ 2.05$ (46.9\%) in the intervention and control groups, respectively. Based on the change observed in the control group, the expected new prescription PMPM cost for the intervention group was $\$ 6.45$ (Table 3). During the study period, the intervention group accounted 185,959 member-months at an average PMPM cost of $\$ 5.88$. The difference between the expected new prescription PMPM expenditures (\$6.45) and the actual new prescription PMPM expenditures (\$5.88) represents savings of \$0.57 PMPM (8.8\%). Over the 12-month period, this difference equals total savings of $\$ 105,997$ or average savings of $\$ 465$ PPPM.

\section{Twelve-Month Analyses of All Pharmacy Claims}

Larger savings were documented when all pharmacy claims were analyzed. Although the intervention and control groups were matched using data from new prescriptions rather than all prescriptions, the average costs for all prescriptions $(74,200$ pharmacy claims) were also similar in the 6-month baseline period prior to implementation of the CDSS (\$46.29 versus \$46.24).

In the follow-up period, the average cost per prescription decreased by $\$ 0.38(-0.8 \%)$ in the intervention group while it increased by $\$ 2.19$ (4.7\%) in the control group. Based on the $4.7 \%$ increase observed in the control group, the expected average cost per prescription in the intervention group was $\$ 48.48$ compared with the actual average cost of $\$ 45.91$ for 76,541 prescriptions in the intervention group (Table 3 ). The difference between the expected cost (\$48.48) and the actual cost ( $\$ 45.91$ ) represents total savings of $\$ 2.57$ per prescription. Based on this difference, the total 12-month savings on all pharmacy claims were $\$ 196,710$ or an average of $\$ 863$ PPPM.

Since there was little difference between the 2 groups in the absolute change in prescription utilization for all pharmacy claims (an increase of 0.03 prescriptions PMPM [7.9\%] in the intervention group versus 0.034 prescriptions PMPM [8.0\%] in the control group) (Table 2), similar results were observed when the savings were calculated on a PMPM basis. During the 12-month follow-up period, PMPM drug costs increased by $\$ 1.22$ (6.9\%) in the intervention group and by $\$ 2.55$ (12.9\%) in the control group. Based on the change observed in the control group, the expected PMPM cost for the intervention group was $\$ 19.97$ compared with the actual average cost of $\$ 18.90$ PMPM for the clinicians in the intervention group (Table 3 ). The difference between the expected PMPM cost (\$19.97) and the actual PMPM cost (\$18.90) represents savings of $\$ 1.07$ PMPM. Over the 12-month period, this difference equals total savings of $\$ 198,976$ or average savings of $\$ 873$ PPPM.

\section{Impact on Other Refilled Prescriptions}

The difference in savings between new prescriptions and all pharmacy claims is due to the system's impact on other refilled prescriptions (i.e., chronic medications that were started prior to implementation of the system). The effect of switching patients from a preexisting higher-cost medication to a lowercost medication will be reflected in the datasets as a decrease in the number of "other refilled prescriptions" (because the old chronic medication is discontinued) and an increase in the number of new prescriptions (because the patient has not had a prior claim for that medication). As shown in Table 2, the total prescription PMPM (i.e., utilization) rates increased by nearly the same amount in both groups during the follow-up period; however, the components driving the increased utilization were different. Specifically, the number of other refilled prescriptions decreased more in the intervention group than the control group $(-3.3 \%$ versus $-0.9 \%)$, while the number of new claims increased slightly more in the intervention group than in the controls (36.2\% versus $34.3 \%$ ). In addition, the PMPM expenditures for older prescriptions decreased by $\$ 0.27(-2.0 \%)$ in the intervention group while they increased by $\$ 0.50$ (3.3\%) in the control group. These findings are consistent with what would be expected if clinicians in the intervention group were switching patients' chronic regimens to lower-cost drug therapies. Although the between-group differences for these outcomes were relatively small compared with those observed for new prescriptions, other refilled prescriptions accounted for more than two thirds of all pharmacy claims; therefore, the impact on these prescriptions contributed significantly to the total savings.

\section{Impact on Savings Over Time}

In all 4 cost analyses, the savings in the last 6 months of follow-up were significantly greater than those observed in the first 6 months of the observation period. The average savings on new prescriptions in the last 6 months of follow-up were $\$ 748$ PPPM and \$794 PPPM, based on differences in the average cost per new prescription and new prescription PMPM expenditures, respectively. For analyses using all pharmacy claims, the savings in the last 6 months of follow-up were $\$ 1,027$ PPPM and \$1,232 PPPM, based on the differences in the average cost per prescription and PMPM expenditures, respectively.

\section{Impact on Prescribing Behavior}

Use of the CDSS was also associated with significant shifts in prescribing behavior. Within the 8 targeted therapeutic categories, prescriptions for high-cost target medications overall decreased by a relative $9.1 \%$ in the intervention group (from $39.4 \%$ to $35.8 \%$ ) and increased by a relative $8.2 \%$ in the control group (from $40.1 \%$ to $43.4 \%$ ). Compared with the control group, the prescription ratio for high-cost drug classes was a relative $17.5 \%$ lower in the group using the CDSS (35.8\% versus $43.4 \%, P=0.03$ ).

Prescribing behavior shifts for the individual targeted therapeutic categories are shown in Table 4. During the study period, the intervention group was significantly less likely than the control group to prescribe proton pump inhibitors 


\section{TABLE $4 \longdiv { \text { Proportion of Prescriptions } }$ for High-Cost (Target) Drugs Within Each Therapeutic Category}

\begin{tabular}{|c|c|c|c|}
\hline Therapeutic Categories & $\begin{array}{c}\text { \% for Baseline } \\
\text { (6 Months: } \\
\text { November 2001- } \\
\text { April 2002) }\end{array}$ & $\begin{array}{l}\text { \% for Follow-up } \\
\text { (12 Months: } \\
\text { June 2002- } \\
\text { May 2003) }\end{array}$ & $\begin{array}{c}\text { Absolute and } \\
\text { Relative Change } \\
\text { in Rx Proportion } \\
\text { From Baseline (\%) }\end{array}$ \\
\hline $\begin{array}{l}\text { Depression (single- } \\
\text { source SSRIs) } \\
\text { Inte nention group } \\
\text { Control group }\end{array}$ & $\begin{array}{l}82.6 \\
80.6\end{array}$ & $\begin{array}{l}66.6 \\
82.9\end{array}$ & $\begin{array}{c}-16.0(-19.4 \%) \\
2.3(2.9 \%)\end{array}$ \\
\hline $\begin{array}{l}\text { GERD (proton pump } \\
\text { inhibitors) } \\
\text { Interention group } \\
\text { Control group }\end{array}$ & $\begin{array}{l}62.7 \\
73.3\end{array}$ & $\begin{array}{c}70.9^{*} \\
87.1\end{array}$ & $\begin{array}{c}8.2(13.1 \%) \\
13.8(18.9 \%) \neq\end{array}$ \\
\hline $\begin{array}{l}\text { Rhinitis (low-sedating } \\
\text { antihistamines) } \\
\text { Inte nention group } \\
\text { Control group }\end{array}$ & $\begin{array}{l}59.6 \\
51.2\end{array}$ & $\begin{array}{l}53.5 \\
57.7\end{array}$ & $\begin{array}{l}-6.1(-10.2 \%) \\
6.5(12.7 \%)\end{array}$ \\
\hline $\begin{array}{l}\text { Infections (broad } \\
\text { spectrum agents) } \\
\text { Inte nention group } \\
\text { Control group }\end{array}$ & $\begin{array}{l}36.2 \\
37.7\end{array}$ & $\begin{array}{l}28.2 \\
34.7\end{array}$ & $\begin{array}{l}-8.0(-22.1 \%) \dagger \\
-3.0(-8.0 \%) \S\end{array}$ \\
\hline $\begin{array}{l}\text { Pain/migraine (COX-2 } \\
\text { inhibitors and triptans) } \\
\text { Intenention group } \\
\text { Control group }\end{array}$ & $\begin{array}{l}25.3 \\
25.4\end{array}$ & $\begin{array}{l}22.8 \\
35.2\end{array}$ & $\begin{array}{l}-2.5(-9.9 \%) \\
9.8(38.6 \%)\end{array}$ \\
\hline $\begin{array}{l}\text { Hypertension (ARBs } \\
\text { and CCBs) } \\
\text { Int enention group } \\
\text { Control group }\end{array}$ & $\begin{array}{l}20.8 \\
26.6\end{array}$ & $\begin{array}{c}13.6^{*} \\
20.9\end{array}$ & $\begin{array}{l}-7.2(-34.6 \%) \ddagger \\
-5.7(-21.4 \%) \S\end{array}$ \\
\hline $\begin{array}{l}\text { Asthma (leukotriene } \\
\text { receptor antagonists) } \\
\text { Inte nention group } \\
\text { Control group }\end{array}$ & $\begin{array}{l}16.8 \\
16.0\end{array}$ & $\begin{array}{l}24.3 \\
21.2\end{array}$ & $\begin{array}{l}7.5(44.6 \%) \\
5.2(32.5 \%)\end{array}$ \\
\hline $\begin{array}{l}\text { Diabetes } \\
\text { (thiazolidinediones) } \\
\text { Intenention group } \\
\text { Control group }\end{array}$ & $\begin{array}{l}7.8 \\
6.4\end{array}$ & $\begin{array}{l}5.4^{*} \\
20.3\end{array}$ & $\begin{array}{l}-2.4(-30.8 \%) \\
13.9(217.2 \%) \S\end{array}$ \\
\hline $\begin{array}{l}\text { Total for all high-cost } \\
\text { target categories } \\
\text { Inte nention group } \\
\text { Control group }\end{array}$ & $\begin{array}{l}39.4 \\
40.1\end{array}$ & $\begin{array}{c}35.8 \dagger \\
43.4\end{array}$ & $\begin{array}{c}-3.6(-9.1 \%) \\
3.3(8.2 \%)\end{array}$ \\
\hline
\end{tabular}

The ratios are derived from the number of new prescriptions for high-cost therapies divided by the number of total new prescriptions for each therapeutic category (prescriptions for high-cost therapies + recommended therapies). All $P$ values were adjusted for the impact of patient clustering. $P>0.1$ for all baseline comparisons, except hypertension $(P=0.05)$.

* $P<0.01$ for difference between groups during the study period.

$\dagger P<0.05$ for difference between groups during the study period.

$¥ P<0.01$ for comparison between baseline and study period.

$\S P<0.05$ for comparison between baseline and study period.

$A R B=$ angiotensin receptor blocker; $C C B=$ calcium channel blocker; COX-2 = cyclooxygenase $-2 ; G E R D=$ gastroesophageal reflux disease;

$R x=$ prescription; $S S R I=$ selective serotonin reuptake inhibitor
$(P=0.002)$, high-cost antihypertensives $(P=0.004)$, and glitazones $(P=0.004)$. Compared with the baseline, the control group's use of proton pump inhibitors $(P=0.003)$ and glitazones $(P=0.02)$ increased significantly during the follow-up period, whereas in the intervention group, there was a nonsignificant increase in the use of the proton pump inhibitors $(P=0.2)$ and a nonsignificant decrease in the use of glitazones $(P=0.087)$. The use of broad-spectrum antibiotics decreased significantly in the intervention $(P<0.001)$ and control groups $(P=0.04)$ compared with baseline, as did the use of high-cost antihypertensives $(P=0.003$ for the intervention group and $P=0.03$ for the control group).

\section{Discussion}

Providing evidence-based decision support during the electronic prescribing process can have a significant impact on prescribing decisions and prescription costs. In this study, the average drug costs savings during the first year of use exceeded \$850 PPPM. As expected, most of the savings were due to interventions targeting new prescriptions; however, there also appeared to be a small impact on the use of chronic medications that were started prior to implementation of the system. The relative reduction in the volume and cost of these previous drug therapies is most likely the result of messages that recommend switching patients to more cost-effective therapies, discontinuing unnecessary high-cost medications, and optimizing the dosing of current therapies. It is also important to note that the number of new prescriptions continuously increases over time as more patients visit their physicians, are diagnosed with new clinical conditions, and are started on new medications (or switched from an old prescription to a new prescription). In our study, new prescriptions (for drugs not previously used by a given patient) were continuously replacing old prescriptions. For example, new prescriptions accounted for $22 \%$ to $27 \%$ of claims in any 6 -month period, $31 \%$ to $36 \%$ of claims in any 12 -month period, and $39 \%$ to $43 \%$ of claims at 18 months (i.e., the 6-month baseline period plus 12-month follow-up period). Because savings in the last 6 months of follow-up were consistently higher than those observed in the first half of the year, it is possible that a longer study would have documented even greater savings.

The system also had a significant impact on the use of heavily promoted, high-cost therapies. This is a critical finding, as several published trials have reported that other CDSS were not able to significantly influence prescribing behavior. $3,6,9,13,14,20$ In addition, an unpublished trial reported that an electronic prescribing system without integrated decision support or messaging capabilities produced no demonstrable impact on prescribing behavior. ${ }^{21}$ Interestingly, the CDSS used in our study was successful at changing prescribing behavior without the use of forcing functions, pop-up windows, or any other feature that directly interfered with the prescribing process or required 
action by the physician. The system simply described the evidence behind the recommendations and let physicians choose the most appropriate action.

Strengths of this study include the evaluation of a commercially available CDSS in a community-based primary care setting, inclusion of a carefully matched control group, reliance on pharmacy claims data, evaluation of a wide range of prescribing decisions, and demonstration of sustained improvements over 12 months of follow-up. As stated earlier, most previous studies have been conducted in hospital or academically affiliated settings, used an internally developed CDSS that cannot be easily exported to other settings, limited their interventions to a single drug class or disease state, or provided relatively short follow-up.., $6-6-14$

It is also important to note that the clinicians in this study received no personal financial incentives to use the CDSS or to change their prescribing behavior, and they were not involved in the creation of any of the clinical content. In addition, the intervention and control groups practiced in the same geographic regions, were managed under the same health plan restrictions, and were unaware that their prescribing behavior was being monitored. These attributes suggest the results may be generalized to other practice settings.

\section{Limitations}

The most notable limitations of this study include the relatively small number of clinicians, the absence of random assignment of clinicians to intervention (CDSS) and control groups, and the inclusion of some prescriptions written on the CDSS in the control group during the second 6 months of the 12-month observation period. The CDSS was implemented at Affinity Health System in several phases, with approximately 100 clinicians added to the CDSS throughout the 12-month follow-up period of our study. This rolling implementation process made it impossible to randomize clinicians to intervention or control status. There were a large number of clinicians using the system by the end of the follow-up period, but the present evaluation was limited to the 38 clinicians who were included in the original study. The higher ratio of internal medicine physicians (37\%) in the control group compared with the intervention group (16\%) may have contributed to the $11.4 \%$ higher baseline PMPM drug cost ( $\$ 19.70$ versus $\$ 17.68$, respectively); however, the baseline characteristics for these control clinicians provided a closer match to the intervention group than any other eligible controls.

Our small sample size of prescribers may have prevented some of the comparisons of prescribing behavior outcomes from reaching statistical significance, even within drug classes for which there appeared to be a clinically meaningful effect. Despite the small number of physicians in each group, the final analysis included a large number of prescriptions $(156,429)$ and a large number of members $(29,985)$. These numbers underscore how interventions with even a small number of physicians can affect a large number of patients.

The fact that some of the clinicians in the control group started using the CDSS during the second half of the follow-up period may have confounded our results. Following implementation of the CDSS in these 15 control clinicians, the prescription ratio for high-cost drug classes was a relative $11.0 \%$ lower (39.6\% versus $44.5 \%$, data not presented in the tables), and their average new prescription cost was $\$ 3.46$ lower ( $\$ 47.04$ versus $\$ 50.50$, data not presented in the tables) than it had been prior to implementation. These data suggest that the system was beginning to influence the prescribing behavior of controls as they crossed over to become CDSS users. As a result, the actual savings associated with the CDSS may be understated in our analyses. On the other hand, we did not have sufficient detail available to perform statistical analyses on PMPM costs and for all pharmacy claims (including older prescriptions that were active prior to the intervention). Although the savings related to these outcomes appear to be meaningful, we cannot be confident that they would have reached statistical significance.

All data were based on the date that patients filled their prescriptions (fill date) rather than the date that the prescription was written. Given the large number of prescriptions analyzed and the fact that the prescription fill date was used for both groups, it seems unlikely that this discrepancy would substantially change our results. Nevertheless, it is possible that some prescriptions attributed to the CDSS were written prior to implementation. Likewise, it is possible that some prescriptions written on the CDSS were not filled prior to the end of the follow-up observation period.

It is also important to note that the savings were based on the actual drug ingredient cost for each prescription. We did not correct our prescription cost analyses for a standardized 30-day supply because the days supply values were not available for all of our analyses. However, within the new prescription analyses, the average days supply per prescription were similar between the intervention and control groups at baseline ( 24.72 versus 24.78 days) and throughout the 12 -month follow-up period (26.17 versus 26.12 days). This finding, coupled with the similarities between the savings estimates using all pharmacy claims and our calculation of PMPM expenditures over a 12-month period, suggests that these adjustments for a standardized 30-day supply would not have affected our primary results.

Finally, the savings reported from our trial are limited to prescription costs for a single health plan. We did not estimate implementation costs, but we also did not attempt to estimate the value of other potential benefits that could be achieved through the use of CDSS such as the potential for reducing prescribing errors, possible avoidance of drug-drug interactions, improvements in quality of care, or enhanced physician office efficiencies related to the automated refill process and reduced call-backs to pharmacies. 
It is possible that the savings documented in this study underestimate the total benefits from improved quality and cost outcomes for patients and the health care system.

\section{Conclusion}

Providing diagnosis-specific messages to physicians during the electronic prescribing process can shift prescribing to lower-cost prescriptions. The savings on medication cost alone overwhelmed the monthly subscription fee for the electronic prescribing system.

\section{ACKNOWLEDGMENTS}

The authors gratefully acknowledge Jennifer Resch, BA, Affinity Health System, for her assistance with data collection; Brian Waterman, MPH, Waterman Research Solutions, for his assistance with the statistical analysis; and Thomas Doerr, MD, Esse Health and Purkinje, for his thoughtful review of the manuscript.

\section{DISCLOSURES}

This study was presented, in part, at the National Committee on Vital and Health Statistics Subcommittee on Standards and Security meeting, May 26, 2004, in Washington, DC. No outside funding supported this study. Authors S. Troy McMullin and Thomas P. Lonergan are employees of Purkinje (formally known as WELLINX), distributor of the electronic decision support tool that was the subject of this study; author Charles S. Rynearson, discloses no potential bias or conflict of interest relating to this article.

McMullin served as principal author of the study. Study concept and design were contributed by all authors. Analysis and interpretation of data were contributed by McMullin and Lonergan. Drafting of the manuscript was primarily the work of McMullin, and its critical revision was the work of Lonergan and Rynearson. Statistical expertise was contributed by McMullin and Brian Waterman, and administrative, technical, and/or material support was provided by McMullin and Rynearson.

\section{REFERENCES}

1. Johnston ME, Langton KB, Haynes RB, Mathieu A. Effects of computerbased clinical decision support systems on physician performance and patient outcome. A critical appraisal of research. Ann Intern Med. 1994;120:135-42.

2. Hunt DL, Haynes B, Hanna SE, Smith K. Effects of computer-based clinical decision support systems on physician performance and patient outcomes. A systematic review. JAMA. 1998;280:1339-46.

3. Teich JM, Merchia PR, Schmiz JL, et al. Effects of computerized physician order entry on prescribing practices. Arch Intern Med. 2000;160:2741-47.

4. Kaushal R, Shojania KG, Bates DW. Effects of computerized physician order entry and clinical decision support systems on medication safety. Arch Intern Med. 2003;163:1409-16.

5. Kuperman GJ, Gibson RF. Computer physician order entry: benefits, costs, and issues. Ann Intern Med. 2003;139:313-19.
6. Hobbs FD, Delaney BC, Carson A, Kenkre JE. A prospective controlled trial of computerized decision support for lipid management in primary care. Fam Pract. 1996;13:133-37.

7. Rossi RA, Every NR. A computerized intervention to decrease the use of calcium channel blockers in hypertension. J Gen Intern Med. 1997;12:672-78.

8. Montgomery AA, Fahey T, Peters TJ, MacIntosh C, Sharp DJ. Evaluation of a computer based clinical decision support system and risk chart for management of hypertension in primary care: randomized controlled trial. BMJ. 2000;320:686-90

9. Eccles M, McColl E, Steen N, et al. Effect of computerized evidence based guidelines on management of asthma and angina in adults in primary care: cluster randomized controlled trial. BMJ. 2002;325:941-47

10. Filippi A, Sabatini A, Badioli L, et al. Effects of an automated electronic reminder in changing antiplatelet drug prescribing behavior among Italian general practioners in diabetic patients: an intervention trial. Diabetes Care. 2003;26:1497-1500

11. Kralj B, Iverson D, Hotz K, Ashbury FD. The impact of computerized clinical reminders on physician prescribing behavior: evidence from community oncology practice. Am J Med Qual. 2003;18:197-203.

12. Fischer MA, Solomon MA, Teich JM, Avorn J. Conversion from intravenous to oral medications: assessment of a computerized intervention for hospitalized patients. Arch Intern Med. 2003;163:2585-89.

13. Tierney WM, Overhage JM, Murray MD, et al. Effects of computerized guidelines for managing heart disease in primary care. J Gen Intern Med. 2004; 18:967-76

14. Weir CJ, Lees KR, MacWalter RS. Cluster-randomized, controlled trial of computer-based decision support for selecting long-term anti-thrombotic therapy after acute ischemic stroke. QJM. 2003;96:143-53.

15. McMullin ST, Lonergan TC, Rynearson CS, et al. Impact of an evidencebased computerized decision support system on primary care prescription costs. Ann Fam Med. 2004;2:494-98.

16. Chuang JH, Hripcsak G, Heitjan DF. Design and analysis of controlled trials in naturally clustered environments: implications for medical informatics. J Am Med Inform Assoc. 2002;9:230-38.

17. Divine GW. The unit of analysis error in studies about physicians' patient care behavior. J Gen Intern Med. 1992;7:623-29.

18. Murray DM. Design and Analysis of Group-Randomized Trials. New York: Oxford University Press; 1998.

19. Medicare program: solicitation for proposals for the physician group demonstration project. Fed Regist. 2002;67:61116-29.

20. Bates DW, Kuperman GJ, Wang S. The Ten Commandments for effective clinical decision support: making evidence-based medicine a reality. J Am Med Inform Assoc. 2003;10:523-30.

21. Ross Michael S, Papshev D, Murphy EL, et al. Effects of electronic prescribing on formulary compliance in the ambulatory setting: a retrospective claims analysis. Available at: www.advancedconceptsinstitute.com. Accessed April 12, 2005. 